\title{
The Zero Lower Bound, ECB Interest Rate Policy and the Financial Crisis
}

\author{
Stefan Gerlach \\ John Lewis \\ Institute for Monetary and Financial Stability \\ Goethe University of Frankfurt, \\ Economics and Research Division \\ De Nederlandsche Bank \\ CEPR and CFS
}

Revised March 10, 2010

\begin{abstract}
This paper estimates a monetary policy reaction function for the ECB over the period 1999-2009. To allow for a potential shift in interest rate setting during the financial crisis, we permit a smooth transition from one set of parameters to another. The estimates show a swift change in the months following the collapse of Lehmann brothers and that the ECB cut rates more aggressively than expected solely on the basis of the worsening of macroeconomic conditions, consistent with the theoretical literature on optimal monetary policy in the vicinity of the zero bound.
\end{abstract}

Keywords: ECB, reaction functions, ordered logit, smooth transition. JEL Number: C2, E52

We are grateful to Beate Bierut, Kerstin Bernoth, Petra Gerlach-Kristen, Andreas Pick and seminar participants at DIW and the ECB for useful comments, and to Chris Williamson at Markit for the PMI data. The support of the DNB's visiting scholar programme is gratefully acknowledged.

Contact information: Stefan Gerlach, IMFS, Goethe University, Grüneburgplatz 1 (Box H 12), 60629 Frankfurt/Main, Germany, email: Stefan.Gerlach@wiwi.unifrankfurt.de, tel +4969 798 34500, fax: +4969 798 34502; John Lewis, Economics and Research Division, De Nederlandsche Bank, P.O: Box 981000 AB, Amsterdam, The Netherlands, email: j.m.lewis@dnb.nl, tel+31 20524 2835, fax: +31 205242506. 


\section{Introduction}

Following the collapse of Lehman Brothers in September 2008, central banks across the world initiated a series of large interest rates cuts. Two related factors may have placed a role in this episode. Most obviously, the sharp falls in headline inflation and economic activity warranted a correspondingly strong policy response to support growth and to ensure that inflation would return to the desired level. Furthermore, and more interestingly, central banks may have perceived a risk that policy rates may eventually reach the zero lower bound (ZLB) and therefore altered their interest rate setting behaviour. ${ }^{1}$

Whether and how monetary policy should change in the run-up to the ZLB has been the subject of intense debate. On the one hand, some have argued that the prospect of reaching the ZLB calls for central banks to "keep their gun powder dry" and be more cautious in cutting rates. On the other hand, the theoretical literature on optimal monetary policy argues that interest rates in this case should be cut faster and more aggressively than suggested by macroeconomic conditions.

The recent experiences therefore provide an opportunity to test whether the predictions of the existing theoretical literature are consistent with observed interest rate setting behaviour in the vicinity of the lower bound. In this paper we seek to perform such a test, focussing on the rate setting of the ECB in the period 1999-2009, that is, before and during the current financial crisis. We estimate a reaction function for the ECB using a smooth transition methodology that allows for a

1 In the theoretical literature, the notion of a "zero lower bound" is interpreted literally. In practice, however, central banks appear to push interest down to a very low but positive level, say 10-30 basis points. It may therefore be more appropriate to refer to a "lower bound." 
gradual shift between a pre-crisis and a crisis regime. This enables us to estimate whether and, if so, when and how rapidly a shift in reaction function occurred.

In the paper we focus on a potential switch to a crisis regime. Many macroeconomic variables, in particular those capturing real economic conditions, have by now recovered to levels similar to, or above, those observed before the massive interest rate cuts in the end of 2008. One might therefore interpret the fact that the ECB has not raised interest rates as evidence against the model. However, theory suggests an important asymmetry in that the variables that predict a shift in the reaction function into a "crisis" mode need not be useful for prediction a return to the original reaction function. The reason for this is that in order to support economic conditions, central banks may keep short-term interest rates low also after the economy has started to recover in order to prevent long-term interest rates from rising too rapidly. It thus may be too early to study a potential switch back to the pre-crisis regime.

We begin by estimating the switch as a function of time and find strong evidence for such a change in the autumn of 2008 and that it occurred gradually over a period of several months. Testing against the nested alternatives of a discrete break in October 2008 or no change at all, we find that a smooth transition model fits the data significantly better. We then extend this analysis and allow the transition between regimes to depend on real GDP growth rather than time. This approach gives an economic explanation for the switch and, unlike the case in which it is modelled as a deterministic function of time, allows for the switch to be reversed. As one would expect, this model fits the data less well, but the worsening of fit is trivial and the estimated timing and speed of the transition is very similar to that of the first model. The switch is estimated to have occurred when the annual growth rate of real GDP fell to $-1.4 \%$ and is again consistent with a gradual switch during the autumn of 2008 . 
In both cases, we find robust evidence that after the autumn of 2008, interest rates were cut faster and more aggressively than the pre-crisis reaction function would have predicted, even given the sharp deterioration of macroeconomic fundamentals. The results are thus compatible with the notion that at least some of the 22 members of the ECB's Governing Council grew concerned that the ZLB might be reached in the near future. The rapid interest rate cuts are thus compatible with the theoretical literature on optimal monetary policy near the ZLB.

The paper contributes to two distinct strands of the literature. First and foremost, we provide an empirical exploration of the main implication of theoretical literature on optimal monetary policy in the vicinity of the zero bound. Secondly, we update the existing empirical literature on ECB interest rate setting behaviour to include an analysis of the crisis period.

The paper is organised as follows. In Section 2, we briefly review the literatures on monetary policy in the presence of the ZLB and the estimation of reaction functions for the ECB. We also provide a short overview of ECB interest rate setting during the crisis. In Section 3 we outline our estimation strategy, explain our choice of data and discuss how we model the structural change in the reaction function. Section 4 presents the results of our estimations. Finally, Section 5 offers some tentative conclusions.

\section{Preliminaries}

As a prelude to the subsequent discussion, in this section we briefly review the relevant literature on the ZLB, provide a short review of the literature estimation reaction functions for the ECB, and review ECB interest rate decisions from July 2007 onwards, that is, the month before the financial crisis started with a tightening of liquidity in interbank markets worldwide. 


\subsection{The ZLB}

Central banks are unable to reduce interest rates (much) below zero since agents can avoid negative nominal interest rates by holding money rather than interest bearing assets. ${ }^{2}$ This places a floor on interest rates at zero. This issue has been noted as far back as Keynes (1936) and Fischer (1896) and was first emphasised in the modern literature by Summers (1991). ${ }^{3}$ While the ZLB was initially seen as of largely academic interest, the decline in inflation across the world in the late 1990s and the accompanying fall in nominal interest rates triggered a renewed interest in its potential relevance for monetary policy making. The resulting literature focuses on three questions.

A first question concerns the likelihood that the ZLB would be reached. It is easy to see that the lower the central bank's inflation objective and the lower the neutral real interest rate, defined as the real interest rate that would desirable if inflation was at target and the output gap was zero, the greater the likelihood that a contractionary shock would push the policy rate below zero. ${ }^{5}$ The resulting literature concluded that an inflation objective of two percent seemed appropriate. ${ }^{6}$ Not surprisingly, after the onset of the crisis it has been argued that a somewhat higher inflation target,

2 While in theory agents will immediately switch to cash when interest rates turn negative, in practice storage costs mean that interest rates may have to fall somewhat below zero before such a substitution occurs.

3 See Ullersma (2002) for a survey of the literature on the ZLB.

5 Viñals (2001) contains an overview discussion of the consequences of the ZLB. See also Gerlach et al. (2009).

6 See Reifschneider and Williams (2000), Viñals (2001), Coenen et al. (2004), . 
say four percent, would have been preferable since it would have permitted central banks to cut interest rates by more before reaching the zero lower bound. ${ }^{7}$

The second question concerns what other monetary policy tools can be used to expand aggregate demand if policy rates reach zero. A number of authors have argued that even if short-term interest rates have reached zero, a massive expansion of the monetary base is likely to raise aggregate demand, for instance via the prices of financial assets, in particular on the prices of longer-term bonds. ${ }^{8}$ The possibility of depreciating the exchange rate to raise inflation expectations and reduce real interest rates has also received much attention. ${ }^{9}$ The importance of non-monetary policies, in particular fiscal policy, has also been noted. But while this literature has generally concluded that monetary and fiscal policy could be used to expand aggregate demand at the ZLB, there is great uncertainty about the effectiveness of these policies. Furthermore, at the time those papers were written, the only recent episode observed instance of a bank facing the ZLB was that of the Bank of Japan, which did not instil confidence in the efficacy of such non-conventional measures.

In light of this, the third issue addressed is how interest rate policy should be conducted in a situation in which the central bank anticipates that the ZLB might become binding. To clarify the argument, consider the stylised representation in Figure 1. In the absence of a non-negativity constraint on the policy rate, the unconstrained optimal policy rate depends on the state of the macro economy and is denoted by $i^{*}$. The best the central bank can do is to set the actual interest rate, $i$, equal to $i^{*}$ at all points in time.

7 See Blanchard et al. (2010) and Williams (2010).

8 See Orphanides and Wieland (2000).

9 See, for instance, Svensson (2001) or Coenen and Wieland (2003, 2004). 
Suppose next that a severe downturn occurs and that the central bank predicts, $\mathrm{i}^{*}$ to fall below zero as the economy weakens. Faced with this prospect, there are essentially three strategies it can follow.

The first option is to simply follow their current reaction function until the recommended policy rate reaches zero, and then hold rates at zero for as long $\mathrm{i}^{*}$ is negative. This amounts to disregarding the ZLB whenever it does not bind.

The second option is to cut interest rates aggressively to zero once it becomes clear that the ZLB may be reached. In that case the interest rate will follow the dotted line in Figure 1. Thus, as the likelihood the ZLB will bind rises, the central bank cuts interest rates below $\mathrm{i}^{*}$ before it reaches zero.

This strategy is compatible with the recommendations of the literature on optimal monetary policy with a zero bound. Reifschneider and Williams (2000) consider a situation in which monetary policy affects aggregate demand through the long interest rate. If $\mathrm{i}^{*}$ falls below zero, the actual policy rate will exceed the optimal rate, implying that long interest rates will be too high. To counteract this effect, they argue that the central bank should set rates below $i^{*}$ prior to the ZLB being reached.

Adam and Billi (2005) reach a similar conclusion based on the expectations channel using a standard forward-looking New Keynesian model. At low interest rates, forward looking agents anticipate the possibility that future shocks might push the interest rate down to the ZLB. As a result, output and inflation are lowered today. To counteract this amplification mechanism, the central bank must therefore cut rates pre-emptively in order to raise expectations of future inflation and output.

Compatible with this analysis, Orphanides and Wieland (2000) find, using dynamic programming techniques, that the policy rate becomes increasingly sensitive to inflation as it falls and the likelihood that the ZLB will be reached rises. In their 
model, the central bank can use other policy instruments when the ZLB is reached, but not costlessly. Hence in non-deflationary times policymakers are willing to trade off some of their other objectives in order to lower the probability of reaching the ZLB.

Before proceeding and to anticipate some of our empirical results, it is worth noting that the analysis of Reifschneider and Williams (2000) implies that the central bank should be slow to raise interest rates when $\mathrm{i}^{*}$ turns positive.

A third option is for the central bank to behave more cautiously, cutting interest rates by less than the standard reaction function would predict. In that case the interest rate will follow the dashed line in Figure 1. By so doing, the central bank keeps some of its "ammunition" and hence retains the option of interest cuts at a later date. This view is sometimes expressed by policymakers (e.g., Bini Smaghi, 2008). Its proponents argue that aggressive rate cuts may be taken as a sign that the central bank has a more pessimistic view of the economic outlook than market participants and hence induce a worsening of market sentiment. In addition, transmission mechanisms may become much weaker nearer the lower bound, rendering monetary loosening less effective. Finally, keeping rates low for a sustained period of time can fuel future imbalances which are painful to unwind in the tightening phase.

Each of these has a distinct implication for interest rate setting. Under the first strategy, the central bank will set $\mathrm{i}=\mathrm{i}^{*}$ until the ZLB is reached. Under the second strategy, i will fall below $\mathrm{i}^{*}$ as the likelihood that the ZLB will be reached rises and rise only after $i^{*}$ has turned positive. Finally, under the third strategy, $\mathrm{i}$ will rise above $\mathrm{i}^{*}$ as the likelihood that the ZLB will be reached increases.

This suggests that it is possible to discriminate between these approaches by comparing $\mathrm{i}$ and $\mathrm{i}^{*}$ as the latter falls towards zero. Of course, doing so is complicated by the fact that we do not observe $i^{*}$ directly. However, we can compute a model- 
dependent estimate of $i^{*}$ and study the relationship between it and $i$ as the likelihood that the ZLB will be reached increases. Thus, it is principle possible to test whether central banks behaved as suggested by the literature on optimal monetary policy at the ZLB.

This approach requires us to develop a model for $\mathrm{i}$. We do so by estimating a reaction function and therefore next review the literature estimating reaction functions for the ECB.

\subsection{Empirical reaction functions for the $E C B$}

Next we review the substantial literature estimating reaction functions for the ECB to help guide the choice of specification of our reaction function.

The bulk of the literature estimates reaction functions on a monthly basis, since this corresponds to the frequency with which the ECB's Governing Council meets to set rates. Using monthly data is also desirable since it allows us to identify the timing and speed of the switch of any change in the reaction function with much greater precision than quarterly data would.

Of course, the frequency chosen has consequences for the data which are used. Whilst inflation is available at a monthly frequency, data for GDP - and therefore estimated output gaps - are only available quarterly. For this reason some studies use data for industrial production, which is available monthly, to capture the state of the business cycle. However, industrial production data are only available with long 
lags. ${ }^{10}$ Alternatively, one can use subjective measures of real economic conditions, which also are available on a monthly basis. Gerlach (2007) notes that the latter accords with the ECB's own statements which typically stress the importance of "economic sentiment" or "business confidence" rather than output gaps and goes on to show that Eurostats Economic Sentiment Index is highly significant in an empirical reaction function for the ECB.

The early literature typically focussed on comparing ECB rate-setting behaviour after EMU with the average behaviour of the national central banks in the run-up to EMU, on estimated single reaction function or the two periods. ${ }^{11}$ Several of these papers found that the reaction to inflation was below unity, implying that real interest rates fell in response to rising inflation. Another common finding was that the variables that capture real economic conditions are typically highly statistically significant. As suggested by the analysis in Svensson (1997), there are two possible reasons for this. First, the central bank may be concerned about smoothing the business cycle. Second, real economic conditions impact on future inflation through the Phillips curve, implying that even if monetary policy makers were not concerned about output stabilization, they would change interest rates in response to economic activity. Gerlach (2007) argues that measures of the state of the real economy in the Euro area are strongly correlated with inflation concerns expressed in the editorials of the ECB's Monthly Bulletin, which suggests that this is second mechanism is operative.

Several papers have found a strong role for monetary variables, consistent with the second pillar, in ECB interest rate setting. Carstensen (2003) argues that a monetary

10 The data available in the data appendix to the ECB's Monthly Bulletin suggests that the lag is three months.

11 For space reasons we omit a detailed discussion of this literature (e.g. Gerlach and Schnabel, 2000; Peersman and Smets, 1999; Gerdesmeier and Roffia, 2003). See Gerlach (2004) for an overview. 
overhang - but not money growth - has an important role to play. Gerlach (2007) detects a significant influence of monetary growth. In addition, he finds that the ECB has responsed to the rate of depreciation of the nominal effective exchange rate of the euro. Since both money growth and the exchange rate have moved sharply during the crisis, it seems desirable to include them in the model we estimate below.

On the question of whether and how the ECB's reaction function has changed since the current financial crisis the empirical literature is scarce. To our knowledge the only existing work is Gorter et al. (2009). They compare reaction functions estimated prior to the crisis with those estimated over a full sample and find that adding crisis observations to the sample increases the estimated coefficient on inflation. This suggests that the ECB reacted strongly to the decline in inflation in 2008.

\subsection{ECB interest rate decisions, 2007-2009}

How did the ECB's interest rate policy evolve during the crisis? The ECB influences interest rates principally by changing its main refinancing rate (commonly known as the "repo rate"), which is shown in Figure 2 together with the overnight rate since 2007. One striking feature of the figure is that the ECB refrained from cutting rates during the episode of severe money market turbulence in the second half of 2007. For the next 12 months rate the repo rate was kept at $4 \%$, on the grounds of a relatively high rate of HICP inflation, as shown in Figure 3 where we have shaded the crisis period. Furthermore, the ECB raised interest rates to $4.25 \%$ in July 2008 as oil prices continued to rise and putting upward pressure on HICP inflation.

The ECB began reducing rates only in October 2008 when it took part in a coordinated 50 basis point cut by a number of central banks. This cut was explicitly motivated by the ECB in terms of the downside risks to price stability. Subsequent cuts in late 2008 and early 2009 were also justified by the ECB on the basis of falling 
inflationary pressures and the apparent fall in survey based measures of economic sentiment. ${ }^{12}$ These cuts amounted to a very large relaxation of monetary policy of 325 basis points in the space of seven months.

Interestingly, Figure 2 shows that the overnight rate started to decline in advance of the repo rate and falls to a much lower level than the repo rate in 2009. A likely technical reason for this behaviour is that banks took advantage of the ECB's generous provision of term liquidity policy by borrowing more than they needed in order to hedge the risk that tensions in interbank markets would become exacerbated. In turn, they recycled the funds in the overnight market, depressing the overnight rate. But whatever the reason, the ECB appeared not to be concerned by this additional easing of monetary conditions. In what follows we therefore use the overnight rate as the measure of the ECB's monetary policy stance.

Throughout this time the ECB also stressed the separation of interest rate policy and liquidity operations. ${ }^{13}$ As before was the case before the crisis, interest rate decisions were guided by the inflation outlook. Liquidity operations, by contrast, were influenced by the state of money markets and were devoted to ensuring their smooth functioning. That separation implies that financial variables should not therefore feature in an empirical specification of the ECB's reaction function, a conclusion that

12 In the question and answer session on January 15, 2009 President Trichet stated that "[t]his decrease of 50 basis points not only takes into account hard data to date, but also takes into account a continued slowdown of the economy and further alleviation of inflationary expectations.."

13 For example, on 11 September 2007, President Trichet told the European Parliament: "I would like to emphasize that our primary mandate calls for our monetary policy stance to deliver price stability in the medium term. Once the level of interest rates is decided we have the responsibility to ensure the smooth functioning of the segment of the money market that we influence. The two responsibilities are clearly separated and should not be mixed." 
is supported by the fact that interest rates were not cut until October 2008 despite the tensions in the money markets.

In terms of strategy, the ECB has during the crisis laid particular focus on the medium-term inflation outlook as a guide for policymaking. ${ }^{14}$ In addition, it has spoken of a "broad-based" approach, which looks beyond a narrow set of indicators to consider all potential risks to price stability. Both these elements of the framework would seem to permit the altering of monetary policy stance to take into account the challenges posed by the ZLB.

That said, up to now the ECB has refrained from directly discussing the ZLB problem or the appropriate response to it in its official publications. ${ }^{15}$ More broadly, the ECB has typically avoided discussing monetary policy in terms of cutting being fast or slow, or even in terms cycles of tightening and loosening monetary policy, preferring instead to talk only about its most recent interest rate decision. On the other hand, the ECB has never stated that the ZLB does not affect its monetary policy stance. This reluctance to venture an opinion on the ZLB is compatible the view that while some members of the Governing Council were concerned that rates would reach zero, others were not. It is also consistent with the ECB's long standing policy of not commenting on the likely direction of future interest rates.

On a number of occasions the ZLB has come up in the monthly question and answer sessions which follow the Governing Council meeting. On more than one occasion

\footnotetext{
14 "We have a needle in our compass which is very important because, as I have said on many occasions, it is the only one: less than $2 \%$, close to $2 \%$ in the medium term" - Jean Claude Trichet, $15^{\text {th }}$ January 2009.

15 Such an announcement could have had a large effect on confidence. It is therefore not surprising that, even if policy makers were concerned, no such comment was made.
} 
President Trichet has spoken of his desire to avoid a "liquidity trap", but has not elaborated further on how this may affect the ECB's monetary stance, or at what level of rates it sees as a floor. ${ }^{16}$

Individually some members of the ECB's Governing Council have been more forthcoming on how the ZLB should affect monetary strategy although they appear to have reached different conclusions. On the one hand, Bini Smaghi (2008) has spoken of the need to cut cautiously in order to preserve the option of future cuts; whereas Orphanides (2008), consistent with academic work, including his own, has been supportive of a more aggressive response to the economic downturn in the face of the ZLB.

Taken together, this narrative evidence is thus rather agnostic on the question of whether and how the ZLB has affected ECB monetary policymaking. That suggests that empirical analysis might be of particular help in understanding how the ECB has set interest rates during the current financial crisis and whether the possibility that the desired level of the repo rate might become negative has influenced its policy decisions.

\section{The Model}

In this section we discuss the empirical approach. The underlying idea is simple. We estimate a reaction function for the ECB that is allowed to change during the estimation period. We then use the estimated parameters for the period before the crisis and macroeconomic data from the crisis to compute an estimate of $i^{*}$ for the full

\footnotetext{
16 "...[T]aking into account our own economic and financial environment, we are very keen to avoid ending up in a situation that, for us, would not be appropriate, namely a liquidity trap.", Jean Claude Trichet $15^{\text {th }}$ January 2009.
} 
sample and compare that to the actual time path of overnight rates. This approach also yields estimates of the reaction function during the crisis and the time and speed of the switch.

\subsection{Interest Rate Setting}

The starting point for the econometric analysis is a version of the model proposed by Judd and Rudebusch (1998) to study interest rate setting by the Federal Reserve. Let $i_{t}$ denote the EONIA overnight rate and $i_{t}^{T}$ the ECB's "target" for the overnight rate. Let $\pi_{t}, y_{t}, \mu_{t}$ and $\varepsilon_{t}$ denote inflation, real economic activity, money growth and the rate of appreciation of the nominal effective exchange rate. ${ }^{17}$ The target level for the interest rate is given by:

$$
i_{t}^{\mathrm{T}}=\alpha_{0}+\alpha_{\mathrm{y}} \mathrm{y}_{\mathrm{t}}+\alpha_{\pi} \pi_{\mathrm{t}}+\alpha_{\mu} \mu_{\mathrm{t}}+\alpha_{\varepsilon} \varepsilon_{\mathrm{t}}
$$

where $\alpha_{0}, \alpha_{y}, \alpha_{\pi}$ and $\alpha_{\mu}$ are expected to be positive and $\alpha_{\varepsilon}$ negative. Next, the overnight rate is allowed to move gradually towards the target:

$$
\mathrm{i}_{\mathrm{t}}-\mathrm{i}_{\mathrm{t}-1}=\beta_{0}\left(\mathrm{i}_{\mathrm{t}}^{\mathrm{T}}-\mathrm{i}_{\mathrm{t}-1}\right)+\beta_{1} \Delta \mathrm{i}_{\mathrm{t}-1}+\mathrm{e}_{\mathrm{t}}
$$

where $e_{t}$ is a residual. Using equations (1) and (2) we have that:

$$
\mathrm{i}_{\mathrm{t}}=\tilde{\alpha}_{0}+\tilde{\alpha}_{\mathrm{y}} \mathrm{y}_{\mathrm{t}}+\tilde{\alpha}_{\pi} \pi_{\mathrm{t}}+\tilde{\alpha}_{\mu} \mu_{\mathrm{t}}+\tilde{\alpha}_{\varepsilon} \varepsilon_{\mathrm{t}}+\tilde{\alpha}_{\mathrm{i}} \mathrm{i}_{\mathrm{t}-1}+\beta_{1} \Delta \mathrm{i}_{\mathrm{t}-1}+\mathrm{e}_{\mathrm{t}}
$$

where $\tilde{\alpha}_{j} \equiv \alpha_{j} \beta_{0}$ and $\tilde{\alpha}_{i} \equiv\left(1-\beta_{0}\right)$. Before proceeding, we rewrite equation (3) as:

17 Note that the inclusion a variable in the ECB reaction function does not necessarily imply it appears in ECB objective function. Svensson (1997) shows that even if the sole objective of policy is to stabilise inflation around a target, the central bank should react to any variable which may have forecasting power for future inflation 


$$
i_{t}=\Theta Z_{t}+e_{t}
$$

where $\Theta$ is a row vector of parameters and $Z_{t}$ a column vector containing the regressors.

To proceed, one may think of the fitted value equation (4) as a measure of $i^{*}$. However, in estimating this equation, one must take into account the fact that the central bank may have deviated from $i^{*}$ during the sample period because it is concerned that the policy rate may reach the ZLB in the future. To avoid that problem, we estimation the reaction function but allow the parameters in $\Theta$ to change.

\subsection{Modelling Structural Change}

To model structural change, we assume that there are two reaction functions, one in force before, and the other during the financial crisis. During the transition the central bank follows a weighted average of the two with the weights evolving over time in a way we estimate below. Using obvious notation we have that:

$$
\begin{aligned}
& \mathrm{i}_{\mathrm{t}}=\Theta_{\mathrm{I}} \mathrm{Z}_{\mathrm{t}}+\mathrm{e}_{\mathrm{t}} \text { where } \mathrm{e}_{\mathrm{t}} \sim \mathrm{N}\left(0, \sigma_{\mathrm{I}}^{2}\right) \\
& \mathrm{i}_{\mathrm{t}}=\Theta_{\mathrm{II}} \mathrm{Z}_{\mathrm{t}}+\mathrm{e}_{\mathrm{t}} \text { where } \mathrm{e}_{\mathrm{t}} \sim \mathrm{N}\left(0, \sigma_{\mathrm{II}}^{2}\right)
\end{aligned}
$$

Next we turn to the question of how to model any change of the monetary policy reaction function around the time of the onset of the financial crisis. A simple and obvious approach would be to estimate equation (4) with OLS over the full sample and perform Chow tests for a break at plausible dates such as the beginning of the crisis in August 2007 or at the time of the collapse of Lehman Brothers in September 2008. Alternatively, we could use an Andrews test for a break at an unknown date. If we reject the hypothesis of parameter constancy, we can then estimate a reaction 
function for the two subsamples. One unattractive aspect of the first approach is that the date of switch is imposed by the modeller, rather than being estimated. A shortfall common to both approaches is that the break is assumed to be instantaneous. This therefore precludes the possibility that the switch from one regime to another occurred smoothly.

To avoid these problems, we follow Mankiw, Miron and Weil (1987) and use a logistic switching model which produces estimates of both the point in time and the speed at which the transition occurred. ${ }^{18}$ Thus, we assume that the full model can be written as:

$$
i_{t}=\left(1-\omega_{t}\right) \Theta_{I} Z_{t}+\omega_{t} \Theta_{I I} Z_{t}+e_{t}
$$

where the variance of the errors is given by $\sigma^{2}=\left(1-\omega_{t}\right)^{2} \sigma_{I}^{2}+\omega_{t}^{2} \sigma_{I I}^{2}$, implying that the errors are heteroscedastic. The weights obey the logistic function, $\mathrm{L}(\bullet)$ :

$$
\omega_{t}=L\left(\kappa, \lambda, \tau_{t}\right) \equiv \frac{\exp \left(\kappa\left(\tau_{t}-\lambda\right)\right)}{1+\exp \left(\kappa\left(\tau_{t}-\lambda\right)\right)}
$$

where $\tau_{t}$ denotes a time trend. This choice of transition function warrants several comments.

First, since the time trend is increasing monotonically, this reaction function only permits one change between regimes. This seems appropriate in the current context,

18 The focus of their study was how the link between short-term and long-term interest rates was affected by the founding of the Federal Reserve in 1914. An alternative approach would be to employ a Markov switching model. Assenmacher-Wesche (2006) estimates monetary policy reaction functions the Federal Reserve, Bank of England and the Bundesbank using Markov switching. However, estimating a such a model requires that one observes switches from regime I to regime II and back again. Given the short sample of our data, it is difficult to believe that there was a switch back to the pre-crisis regime within the span of our dataset. 
where we are arguably still in the crisis regime. Second, the parameters $\lambda$ and $\kappa$ capture the timing and the speed of the transition respectively. When $\tau_{t}=\lambda$ the logistic function takes the value of $1 / 2$, and hence the transition is exactly half completed. In what follows we refer to this as the switching date. The parameter $\kappa$ captures the duration of the change: Mankiw, Miron and Weil (1987) state that the time between one quarter and three quarters of the adjustment has occurred is given by $\log (9) / \kappa$. Third, this specification nests the case of a discrete break: as $\kappa$ tends to infinity, the speed of adjustment tends also to infinity.

Before proceeding, note that as the model now stands, there is a lack of identification. $\mathrm{L}\left(\kappa_{0} ; \ldots\right) \equiv 1-\mathrm{L}\left(-\kappa_{0} ; \ldots\right)$ and therefore the two models with $\kappa=\kappa_{0}$ and $\kappa=-\kappa_{0}$ will fit the data equally well. When estimating the model, we therefore impose the requirement that $\kappa>0 .{ }^{19}$ This imposes no restrictions on the data.

\subsection{Data}

The review of the literature on estimating reaction functions for the ECB indicated that inflation, money growth, the rate of depreciation of the nominal effective exchange rate and measures of real economic activity are all potential regressors. For inflation, we use the annual percentage change in the Harmonised Index of Consumer Prices (HICP). For money growth, we take the annualised growth rate of M3, and for the nominal exchange rate take the change in the nominal effective

19 We do so by assuming that $\kappa=\exp (\mathrm{K})$ and estimate $\mathrm{K}$. One additional reason for doing that is that below we calculate empirical confidence bands for the transition function using Monte Carlo simulation. When drawing from estimated distribution for the speed parameter, we must ensure that all draws have the same (positive) sign. 
exchange rate index over the previous twelve months. The source for all three variables is the ECB's website.

To measure economic activity we use the Purchasing Manager's Index (PMI) produced by Markit. Although the empirical literature frequently utilises output gaps in empirical reaction functions, the ECB's monthly bulletin rarely refers to these and instead lays much greater stress on indicators of economic sentiment as discussed by Gerlach (2007). Figure 3 plots the euro area PMI together with real GDP growth over four quarters and shows that the two series are strongly correlated. One important difference, however, is that real GDP growth has recovered much more slowly following the onset of the crisis.

While the two series thus contain similar information, using the PMI in reaction functions for the ECB has three important advantages over real GDP growth. First, it is available monthly; real GDP data are only available on a quarterly basis. Second, it is released in the beginning of each month for the previous month. Thus, the reporting lag is minimal in contrast to real GDP data, which are only available with a substantial lag. Third, revisions tend to be small and occur soon after the release of the data; the national accounts data are typically revised several times. These reasons suggest that the PMI is likely to be more strongly correlated with the ECB's view of real economic activity than real GDP, and therefore more suitable for inclusion in the reaction function.

For inflation and the M3, each issue of the monthly bulletin reports provisional data for the previous month, and thus the definitive data are only available with a two 
month lag. Data more than 2 months old are subject to negligible revisions. ${ }^{20}$ Exchange rate data are available with a month's lag, and are not subsequently revised. Accordingly, we lag inflation and M3 growth by two months and the PMI and the exchange rate by one month.

\section{Estimation}

One important feature of the logistic switching model presented above is that the variance of the errors evolves over time in the same way as the parameters. Mankiw, Miron and Weil (1987) propose to estimate the model using maximum likelihood, but in fact use a grid search procedure to determine the parameters in the logistic switching function. Here instead we estimate the full model with maximum likelihood. As starting values, we use the coefficient estimates obtained from estimating the reaction function with OLS.

\subsection{Model estimates: Regime switch as a function of time}

The model estimates are presented in Table 1. The columns headed "pre-crisis" show the reaction coefficients in the first period, $\Theta_{1}$. The columns headed "crisis" show the coefficients in the second period, $\Theta_{2}$. Standard errors and p-values are reported under each coefficient.

We began by estimating an unrestricted model which included the lagged interest rate, the lagged change in the interest rate, HICP inflation, the Purchasing Managers Index (PMI) for the euro area, M3 growth, and the rate of appreciation of the nominal

20 Coenen et al (2005) examine in detail the revisions to both inflation and M3 growth data. They find the former has a mean absolute revision (from time $t+2$ to final data) of two basis points and the latter has a mean absolute revision of eight basis points. 
effective exchange rate of the euro area enter. ${ }^{21}$ Since this function is likely to be heavily overfitted, in particular in the crisis period, we do not comment on it in detail. That said, the coefficients all have the expected signs in the pre-crisis period, but the parameters on inflation and money growth are insignificant. Overall, the equations suggest that monetary policy was tightened in response to higher inflation, faster M3 growth, higher economic activity and a depreciation of the nominal effective exchange rate. The model locates the switch date as November 2008, but cannot identify the speed with any precision. For the second period, the reactions to economic variables are highly insignificant.

We then explored suitable restrictions of the model. Based on the p-values reported for second period coefficients in the restricted case, a natural candidate was to drop in the second period all variables bar the constant and the lagged interest rate. This choice was supported a likelihood ratio test of the implied restrictions. ${ }^{22}$

However, given the wide standard errors in the unrestricted model, it is possible that quite a range of alternative restrictions could also be accepted. For that reason, we also estimated an alternative where all coefficients bar that on the lagged interest rate were equal to the first period values (see appendix, Table A1 for details). However, the value of likelihood function then falls and the posterior odds ratio of such an alternative model is 0.013 . That means that the model with the zero reactions is around 60 times more likely to be the correct one than the one with no change in reactions. We view this as evidence in favour of the first model.

21 All changes and growth rates are measured over 12 months.

22 A chi square test yields $\chi 2(6)=8.947(\mathrm{p}=0.177)$ so the restrictions are accepted. 
Given the debate about the importance of the monetary pillar of ECB's strategy, we also estimated variants of the reaction function which replace inflation with money growth, and which include both inflation and money growth (see appendix for results). These yielded very similar reaction coefficients and estimates of the switch date and speed, suggesting that our headline results are robust to the inclusion of money. However, posterior odds ratio tests suggested using inflation rather than money growth, and hence we omit this variable from our preferred specification.

Our preferred specification is presented on the right hand side of Table 1 . In the precrisis period, the results are as follows. The lagged interest rate is significant with a coefficient of 0.979 which indicates quite a high degree of gradualism in rate setting behaviour. The lagged change in the interest rate is also significant, with a negative sign which is consistent with the finding of Gerlach (2007): ceteris paribus, the ECB is less likely to cut (raise) rates if it did so in the previous month. The coefficient on inflation is positive and strongly significant. ${ }^{23}$ The PMI also enters with a positive and highly significant coefficient, which is consistent with the findings elsewhere in the literature that the ECB pays considerable attention to measures of capacity utilisation as predictors of future inflation. Lastly, there is a significant response to the change in the nominal exchange rate, suggesting the ECB reacts to inflationary pressures generated via the exchange rate channel.

The switching date is estimated to have occurred at a trend value of 225.6, which places the mid point of the switch around November of 2008 (the trend takes the value 225 in October and 226 in November 2008). The speed parameter implies that

23 The long run parameter implied by the coefficients on inflation and the lagged interest rate change is 2.5. This comfortably fulfils the criterion for expectational stability which requires that the long run response to a rise inflation is greater than one. 
the going from 5 to $95 \%$ on the switching function took around four months- i.e. from September 2008 to January 2009. Since the weight attached to the two regimes is a non-linear transformation of $\kappa$ and $\lambda$, it is not easy to see directly how uncertainty about these parameters translates in uncertainty about the weight function. To explore this issue, we compute a confidence band for $\omega$ using simulations. To do so, we take 10,000 draws from the joint distribution of $\lambda$ and $\kappa$ and compute the weights implied by each pair. Figure 5 shows the median of the distribution together with a 95\% confidence band and indicates that the transition took place in the aftermath of the collapse in Lehman Brothers, that is, more than a year after the turbulence in the interbank market in August 2007 which constituted the first sign of the crisis.

To further explore how plausible our estimates for the smooth transition model are, we also estimated two alternative versions. The first of these is a single regime model (which thus assumes that $\omega_{\mathrm{t}}=0$ ), and the second model allows for a discrete break in October 2008 (so that $\kappa \rightarrow \infty$ ). In both cases, likelihood ratio tests strongly reject the restrictions implied (see appendix A2 for details). These results imply that there was a structural break and that it was gradual.

One feature of our preferred model is that in the second, "crisis", regime the interest rate depends solely on its lagged value, a constant and the shock, that is, a first-order auto-regressive model. The fact that the interest rate fluctuates is not surprising since we use a market rate.

The coefficient estimates point to a clear change in the ECB's reaction to economic variables, but they do not tell us directly by how much the interest rate implied by the two reaction functions differs. To better understand the magnitude of the difference in interest rates between regimes, we compare dynamic forecasts from our smooth transition model, with those obtained from a single regime model. 
We obtain these forecasts using simulation methods. We draw 10,000 realisations of the estimated parameters and use these to make dynamic forecasts of the path of the interest rate. ${ }^{24}$ The point forecast is obtained by taking median value for the interest rate, and a 95\% confidence interval around this is obtained by dropping the upper and lower $2.5 \%$ of realisations. The results for our preferred specification are shown in Figure 6.

Several features stand out. First, immediately after the outbreak of tension in euro area money markets in August 2007, the overnight interest rate was somewhat lower than one would have predicted. This presumably reflects the massive liquidityenhancing operations undertaken by the ECB. Second, while the interest rate subsequently remained in the forecast interval, it rose towards the top of the interval after the collapse of Lehman Brothers in September 2008. Both the actual and predicted value of the overnight rate fell rapidly to a low level. Throughout the period, the actual rate remains within the $95 \%$ confidence interval.

Figure 7 shows dynamic in-sample forecasts for the alternative case if there had been no change in reaction function. ${ }^{26}$ As before, the estimation period is from January 1999 to November 2009, and the dynamic forecast is from August 2007 onwards. We think of this dynamic forecast as an estimate of what interest rates would have been if the ECB had not been concerned by the risk of hitting the ZLB and had simply

24 To ensure that the non-negativity constraint on interest rates is respected, if the predicted level of the interest is negative, we set it to zero. Repeating the exercise without the non-negativity constraint on forecast errors does not significantly change the results in this, or other dynamic forecasts considered here.

26 Thus, in constructing these forecasts we use the actual value of all the regressors, except past values of the interest rate, for which we use forecasted values. 
reacted to the sharp deterioration of economic conditions in the same as it responded to economic conditions before the crisis.

In constructing these forecasts, we make two crucial assumptions. First, we assume that the reaction function is correctly specified. Second, we assume that the ECB reacts in a linear fashion to the variables in the reaction function also in cases when they take values that are quite different from those that prevailed in the estimation period. Needless to say, if either of those assumptions are incorrect the actual and the forecasted values for the interest rate can differ.

Whilst these forecasts imply a considerable relaxation monetary policy in response to the sharp worsening macroeconomic conditions, the predicted fall in interest rates is much more gradual and the (vertical) difference between the forecast and actual interest rate is substantial. For instance, in early 2009 the interest rate predicted under the assumption of no change in regime was roughly 200 basis points above the actual rate. Moreover, for most of the period since the collapse of Lehman brothers, the actual rate lay (well) outside the $95 \%$ confidence interval, indicating that the discrepancy between the two is both statistically, as well as economically significant.

These dynamic forecasts suggest that the change in the ECB's reaction function after Lehmann brothers led to significantly lower interest rates than its "old" reaction function would have suggested. The ECB's rate setting strategy appears to have been consistent with the theoretical literature on the ZLB: rates have been cut more aggressively when the possibility of the ZLB looms into view. By the same token, these results seem incompatible with the hypothesis that the ECB exhibited greater caution in rate cutting in order to "keep its gun powder dry."

Overall, our estimates of the timing of the shift accord well with real-time perceptions of the fall-out from the crisis. During the first year of the crisis, i.e. from August 2007 to August 2008, many commentators argued that the ramifications of 
the crisis for the real economy would be relatively small. In this period therefore, one would not expect to see ZLB considerations play a significant role and hence would expect no departure from the regular reaction function. Following the collapse of Lehman Brothers, however, there was a steady deterioration in the outlook over the autumn in 2008 and into early 2009. This led to increased attention to the problem of the ZLB binding in the future, and hence to a change in the monetary policy reaction function.

\subsection{Model estimates: Regime switch as a function of real GDP growth}

So far we have assumed that the weights attached to the reaction functions in the pre-crisis and the crisis periods evolve as a function of time. While our estimates indicate when and how fast the change occurred, they provide no explanation for why the change occurred. As noted earlier, it appears eminently plausible that the shift in the reaction function was triggered by the sharp weakening of the real economy following the collapse of Lehman Brothers in September 2008. Therefore, we now refine the model by making the switch a function of economic activity rather than time.

One candidate measure of economic activity is the PMI but, as already discussed, it recovered very rapidly after the crisis while the ECB maintained interest rates at a low level. Of course, this does not necessarily imply that the PMI is not the correct variable to use to explain the switch in the reaction functions: it may simply be that the ECB has wanted to maintain short-term rates at a low level in order to prevent long-term interest rates from rising rapidly in response to the economic recovery, as suggested by the theoretical literature. However, below we instead use GDP growth 
over twelve months as proxy for whatever considerations may have led the ECB to worry about the risk that the ZLB would be reached. ${ }^{27}$ Denoting real GDP growth with g our weighting function becomes:

$$
\omega_{\mathrm{t}}=\mathrm{L}\left(\mu, \gamma, \mathrm{y}_{\mathrm{t}}\right) \equiv \exp \left(\mu\left(\mathrm{y}_{\mathrm{t}}-\gamma\right)\right) /\left(1+\exp \left(\mu\left(\mathrm{y}_{\mathrm{t}}-\gamma\right)\right)\right)
$$

where $\gamma$ denotes the switching level of GDP growth.

The resulting estimates are shown in Table 2. We began with an unrestricted model. As before, this is likely to be heavily overfitted, so we do not comment in detail on its results. For the pre-crisis period, the reaction coefficients are very similar to those presented in the models in Table 1. Moreover, the post-crisis reaction to all variables (bar the lagged interest rate), is highly insignificant. That again argues in favour of a similar restricted form to that presented in Table 1.

The restriction that the second period reaction to all variables bar the lagged interest is zero is comfortably accepted. Therefore we once again model interest rate setting in the second period as a function of a constant and the lagged rate. The coefficients of both are very close to those in our restricted model in Table 1. The switching point is estimated to have occurred at an annual growth rate of real GDP of $-1.4 \%$.

In the pre-crisis period, the responses of the interest rate to economic variables are also similar to those estimated earlier: there is a significant positive reaction to the PMI, and a strong positive reaction to inflation. Policy also appears to tighten when the nominal exchange rate depreciates.

27 Of course, real GDP is not available on a monthly basis so we interpolated the quarterly data. In future work we will consider observed monthly time series that can account for the shift in the reaction function. 
The implied dynamics of the switch are best seen by graphing the implied transition function over time, along with a confidence band which we compute in the same way as earlier. As Figure 7 shows, the timing and speed of the switch look similar to those estimated when the switch is a function of time, but are naturally somewhat less precise since the shift must now match the behaviour of real GDP growth. Importantly, the estimates suggest a rapid, but not instant, shift in the autumn of 2008.

Dynamic forecasts of the interest rate assuming a shift in the reaction function are provided in Figure 9, and assuming no shift in Figure 10. These bands are slightly wider than those reported in Figures 5 and 6, but otherwise tell a very similar storyi.e. that the actual rate lies well outside the $95 \%$ confidence interval of the single regime model, but matches up closely with the median forecast of the smooth transition model.

\section{Concluding Remarks}

In this paper we have studied the ECB's interest rate setting behaviour during the financial turmoil of 2007-2009. We draw several conclusions.

The estimates indicate that following the rapid worsening of real economic activity in the fall of 2008, a reaction function that captures the ECB's interest rate setting before the crisis erupted starts to overpredict the overnight rate considerably. By contrast, a model that allows the reaction function to shift provides quite accurate dynamic forecasts of the interest rate. Using GDP growth rather than time as a variable to explain the switch produced similar results on the timing, speed and nature of the regime switch.

These findings are compatible with the theoretical literature on optimal monetary policy in the presence of the ZLB, which suggests that the central bank should cut 
more aggressively than its regular reaction function would suggest if it can foresee the ZLB binding in the future. Equally, they clearly reject the hypothesis that rate cutting has been more cautious in the vicinity of the zero bound. That said, these results could also have been generated by a stable but non-linear reaction function. 


\section{References}

Adam, K., and R. Billi. (2006), “Optimal Monetary Policy under Commitment with a Zero Bound on Nominal Interest Rates", Journal of Money, Credit and Banking, 38(7), 1877-1905.

Assenmacher-Wesche, K. (2006), “Estimating Central Banks' Preferences from a Time-Varying Empirical Reaction Function," European Economic Review 50, 19511974.

Blanchard, O., Dell'Arriccia, G., and Mauro, P. (2010) “Rethinking Macroeconomic Policy", IMF Staff Position Note, SPN/10/03.

Bini Smaghi, L. (2008), "Careful with the 'd' words!", speech given in the European Colloquia Series, Venice, 25 November.

Carstensen, K. (2006) “Estimating the ECB Reaction Function", German Economic Review, 7:2, 1-34.

Coenen, G., A. Orphanides and V. Wieland (2004), "Price Stability and Monetary Policy Effectiveness when Nominal Interest Rates are Bounded at Zero," Advances in Macroeconomics , 4, 1-23.

Coenen, G. and V. Wieland (2003), "The zero-interest-rate bound and the role of the exchange rate for monetary policy in Japan," Journal of Monetary Economics 50, 1071-1101.

Coenen, G. and V. Wieland (2004), "Exchange rate policy and the zero bound on nominal interest rates," American Economic Review: Papers and Proceeding 94, 8084. 
Coenen, G., Levin, A., and V. Wieland (2005), "Data uncertainty and the role of money as an information variable for monetary policy, European Economic Review $49: 4,975-1006$.

Fisher, I. (1896) “Appreciation and Interest,” McMillan, New York.

Gerdesmeier, D. and Roffia, B. (2003) “Empirical Estimates of Reaction Functions for the Euro Area", ECB Working Paper No. 206.

Gerlach, S. (2007), "Interest Rate Setting by the ECB, 199-2006: Words and Deeds", International Journal of Central Banking, 3, 1-45.

Gerlach, S. and G. Schnabel (2000), "The Taylor rule and interest rates in the EMU area" Economics Letters, 67(2), 165-171.

Gerlach, S, A. Giovannini, C. Tille, and J. Viñals (2009), Are the Golden Years of Central Banking Over? The Crisis and the Challenges. Geneva Reports on the World Economy 10, ICMB and CEPR.

Gerlach-Kristen, P. (2003) “Interest rate reaction functions and the Taylor rule in the euro area." ECB Working Paper 258.

Gorter, J., J. Jacobs and J. de Haan (2009), “Negative Rates for the Euro Area”, Central Banking, 20:2, 61-66.

Judd, J. and G. Rudebusch (1998), “Taylor's Rule and the Fed: 1970-1997”, Federal Reserve Bank of San Francisco Economic Review, No. 3. 3-16

Keynes, J. (1936), "The General Theory of Employment, Interest and Money" Cambridge University Press, Cambridge. 
Mankiw, N., J. Miron and D. Weil (1987), "The Adjustment of Expectations to a Change in Regime: A Study of the Founding of the Federal Reserve," American Economic Review, 77(3), 358-374

Orphanides, A. and V. Wieland (2000), "Efficient Monetary Policy Design Near Price Stability", Journal of the Japanese and International Economies, 14, 327-365.

Orphanides, A. (2009), "The International Financial Turmoil and the Economy", speech given in Limassol, 28 January 2009.

Peersman, G. and F. Smets (1999), “The Taylor Rule: A Useful Monetary Policy Benchmark for the Euro Area?" International Finance, 2, 85-116.

Summers, L. (1991) “How Should Long-Term Monetary Policy Be Determined?" Journal of Money, Credit and Banking 23 (3): 625-31.

Svensson, L. O. E. (1997), "Inflation Forecast Targeting: Implementing and Monitoring Inflation Targets," European Economic Review 41 (1997) 1111-1146.

Svensson, L. O. E. (1997), “The Zero Bound in an Open Economy: A Foolproof Way of Escaping from a Liquidity Trap," Monetary and Economic Studies 19(S-1), February 2001, 277-312.

Reifschneider, D. and Williams, J. (2000) “Three Lessons for Monetary Policy in a Low-Inflation Era“, Journal of Money, Credit and Banking 32:4, 936-966.

Ullersma, C. (2002), “The zero bound on nominal interest rates and monetary policy effectiveness: a survey", De Economist, 150 (3), 273-297.

Viñals, José (2001), 'Monetary Policy Issues in a Low Inflation Environment,' in A. García Herrero, V. Gaspar, L .Hoogduin, J. Morgan and B. Winkler, (eds) Why Price Stability? ECB, Frankfurt. 
Williams, J. (2010), “Heeding Daedalus: Optimal Inflation and the Zero Lower Bound", Brookings Papers on Economic Activity, forthcoming. 
Figure 1: Actual and hypothetical interest rate

\section{Interest rate}

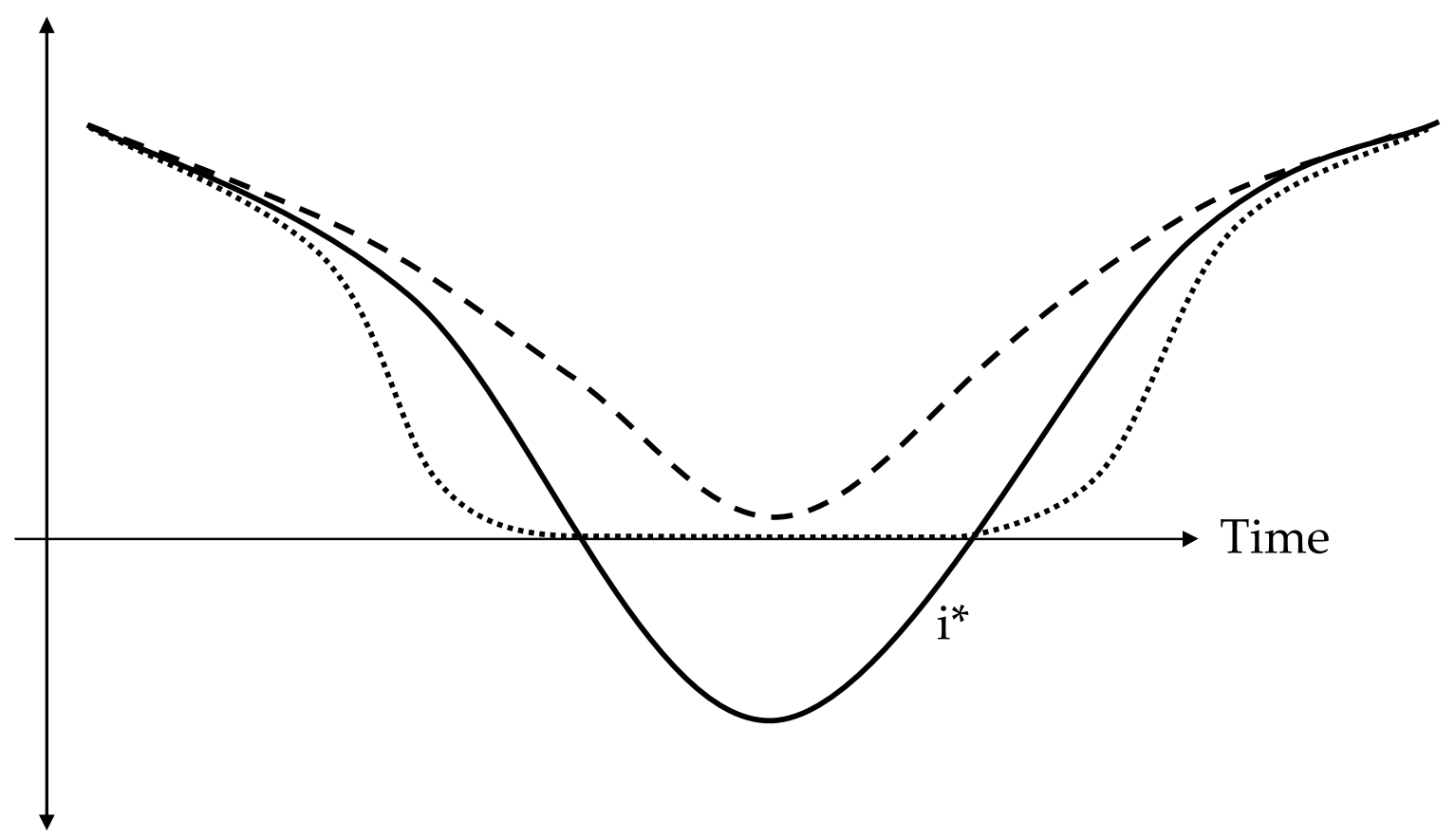




\section{Tables and Figures}

Figure 1: Repo Rate 2007-2009

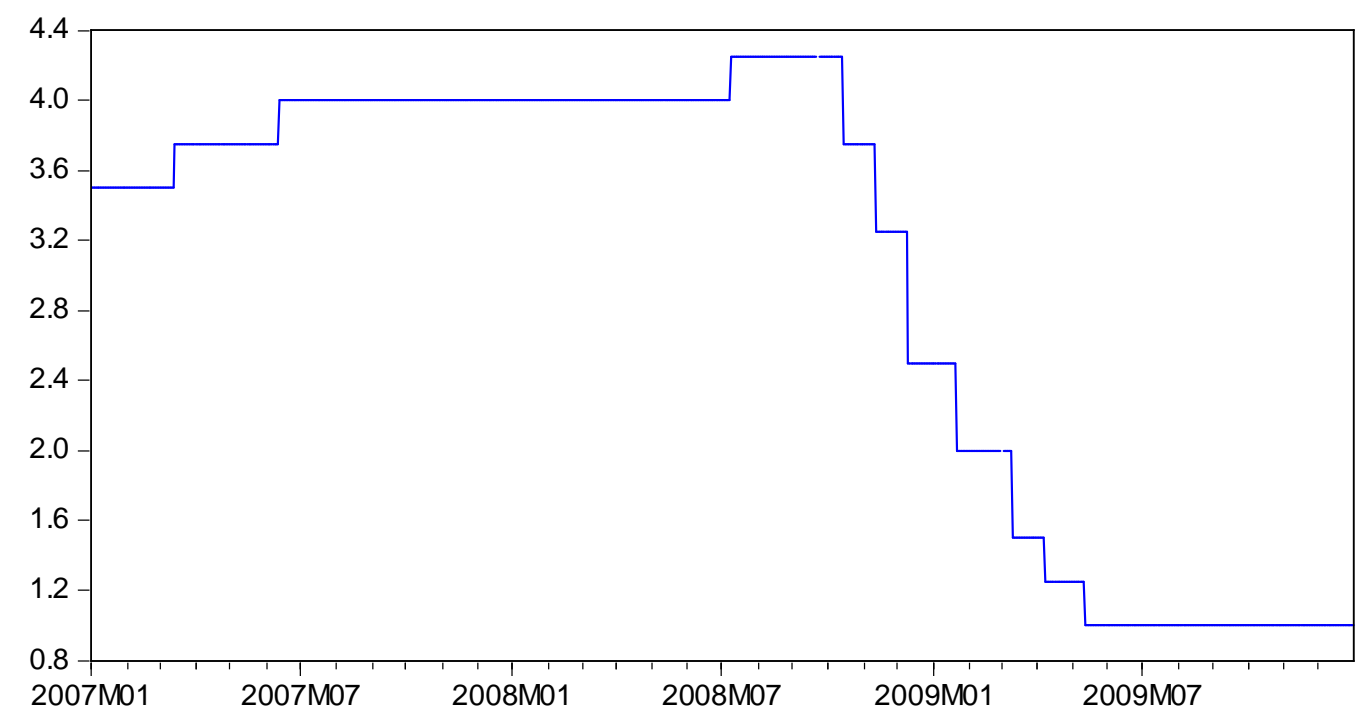


Table 1: Maximum likelihood estimates (Switch as a function of time) Sample period January 1999 - November 2009

\begin{tabular}{|c|c|c|c|c|}
\hline \multirow[b]{2}{*}{ Regime } & \multicolumn{2}{|c|}{ Unrestricted model } & \multicolumn{2}{|c|}{ Restricted model } \\
\hline & Pre-crisis & Post Crisis & Pre-crisis & Post Crisis \\
\hline Constant & $\begin{array}{c}\mathbf{- 1 . 3 3 2} \\
(0.27) 0.00\end{array}$ & $\begin{array}{c}\mathbf{- 0 . 0 5 4} \\
(0.99) 0.00\end{array}$ & $\begin{array}{c}\mathbf{- 1 . 3 9 8} \\
(0.26) 0.00\end{array}$ & $\begin{array}{c}\mathbf{0 . 0 8} \\
(0.10) 0.00\end{array}$ \\
\hline Lagged interest rate & $\begin{array}{c}\mathbf{0 . 9 8 0} \\
(0.01) 0.00\end{array}$ & $\begin{array}{c}\mathbf{0 . 5 7 0} \\
(0.39) 0.14\end{array}$ & $\begin{array}{c}\mathbf{0 . 9 7 9} \\
(0.01) 0.00\end{array}$ & $\begin{array}{c}\mathbf{0 . 7 1 6} \\
(0.06) 0.00\end{array}$ \\
\hline $\begin{array}{l}\text { Lagged change in } \\
\text { interest rate }\end{array}$ & $\begin{array}{c}-\mathbf{0 . 2 8 3} \\
(0.08) 0.00\end{array}$ & $\begin{array}{c}\mathbf{- 0 . 0 4} \\
(0.03) 0.74\end{array}$ & $\begin{array}{c}-\mathbf{0 . 2 7 3} \\
(0.08) 0.00\end{array}$ & \\
\hline PMI & $\begin{array}{c}\mathbf{0 . 0 2 4} \\
(0.01) 0.00\end{array}$ & $\begin{array}{c}\mathbf{0 . 0 0 8} \\
(0.02) 0.67\end{array}$ & $\begin{array}{c}\mathbf{0 . 0 2 6} \\
(0.00) 0.00\end{array}$ & \\
\hline Inflation & $\begin{array}{c}\mathbf{0 . 0 4 2} \\
(0.02) 0.03\end{array}$ & $\begin{array}{c}\mathbf{0 . 2 3 3} \\
(0.30) 0.43\end{array}$ & $\begin{array}{c}\mathbf{0 . 0 5 3} \\
(0.02) 0.00\end{array}$ & \\
\hline M3 growth & $\begin{array}{c}\mathbf{0 . 0 1 0} \\
(0.01) 0.15\end{array}$ & $\begin{array}{c}-\mathbf{0 . 0 4 2} \\
(0.14) 0.75\end{array}$ & & \\
\hline $\begin{array}{l}\text { Nom. eff. exchange } \\
\text { rate }\end{array}$ & $\begin{array}{c}-0.007 \\
(0.00) 0.02\end{array}$ & $\begin{array}{c}-\mathbf{0 . 0 1 1} \\
(0.03) 0.74\end{array}$ & $\begin{array}{c}-\mathbf{0 . 0 0 5} \\
(0.00) 0.05\end{array}$ & \\
\hline $\begin{array}{l}\text { Standard deviation } \\
\text { of error term }\end{array}$ & $\begin{array}{c}\mathbf{0 . 1 0 4} \\
(0.01) 0.00\end{array}$ & $\begin{array}{c}\mathbf{0 . 0 7 6} \\
(0.03) 0.00\end{array}$ & $\begin{array}{c}\mathbf{0 . 1 0 6} \\
(0.01) 0.00\end{array}$ & $\begin{array}{c}\mathbf{0 . 0 8 7} \\
(0.03) 0.00\end{array}$ \\
\hline Speed (K) & & & & \\
\hline Switching date $(\lambda)$ & & & & \\
\hline Log likelihood & & & & \\
\hline
\end{tabular}

Notes: Standard errors in parenthesis; $\mathrm{p}$-values in italics 
Table 2: Maximum likelihood estimates (Switch as a function of GDP growth) Sample period January 1999 - November 2009

\begin{tabular}{|c|c|c|c|c|}
\hline \multirow[b]{2}{*}{ Regime } & \multicolumn{2}{|c|}{ Unrestricted model } & \multicolumn{2}{|c|}{ Restricted model } \\
\hline & Pre-crisis & Post Crisis & Pre-crisis & Post Crisis \\
\hline \multirow[t]{2}{*}{ Constant } & -1.328 & 1.22 & -1.385 & 0.060 \\
\hline & (0.27) 0.00 & (3.28) 0.71 & (0.27) 0.00 & (0.11) 0.58 \\
\hline \multirow{2}{*}{ Lagged interest rate } & 0.978 & 0.81 & 0.979 & 0.734 \\
\hline & (0.01) 0.00 & (5.41) 0.00 & (0.01) 0.00 & (0.06) 0.00 \\
\hline \multirow{2}{*}{$\begin{array}{l}\text { Lagged change in } \\
\text { interest rate }\end{array}$} & -0.284 & -0.06 & -0.275 & \\
\hline & (0.08) 0.00 & (9.49) 0.99 & (0.07) 0.00 & \\
\hline \multirow[t]{2}{*}{ PMI } & 0.024 & -0.006 & 0.026 & \\
\hline & (0.00) 0.00 & (0.48) 0.99 & (0.00) 0.00 & \\
\hline \multirow[t]{2}{*}{ Inflation } & 0.042 & 0.010 & 0.052 & \\
\hline & (0.02) 0.02 & (5.01) 0.99 & (0.02) 0.00 & \\
\hline \multirow[t]{2}{*}{ M3 growth } & 0.009 & -0.014 & & \\
\hline & (0.01) 0.15 & (-0.01) 0.98 & & \\
\hline \multirow{2}{*}{$\begin{array}{l}\text { Nom. eff. exchange } \\
\text { rate }\end{array}$} & -0.007 & -0.06 & -0.005 & \\
\hline & (0.00) 0.02 & (9.50) 0.87 & (0.00) 0.00 & \\
\hline \multirow{2}{*}{$\begin{array}{l}\text { Standard deviation } \\
\text { of error term }\end{array}$} & 0.104 & 0.084 & 0.106 & 0.097 \\
\hline & (0.01) 0.00 & (0.04) 0.04 & (0.01) 0.00 & (0.05) 0.03 \\
\hline \multirow[t]{2}{*}{ Speed (G) } & \multicolumn{2}{|c|}{6.235} & \multicolumn{2}{|c|}{5.402} \\
\hline & \multicolumn{2}{|c|}{ (3.39) 0.06} & \multicolumn{2}{|c|}{ (0.56) 0.00} \\
\hline \multirow{2}{*}{$\begin{array}{l}\text { Switching level of } \\
\text { GDP growth }(\mu)\end{array}$} & \multirow{2}{*}{\multicolumn{2}{|c|}{$\begin{array}{c}\mathbf{0 . 0 1 4} \\
(0.02) 0.66\end{array}$}} & \multicolumn{2}{|c|}{0.014} \\
\hline & & & & \\
\hline Log likelihood & \multicolumn{2}{|c|}{111.27} & \multicolumn{2}{|c|}{107.96} \\
\hline
\end{tabular}




\section{Appendix: Additional Empirical Results}

Table A1: Reaction Functions with Monetary Growth

\begin{tabular}{|c|c|c|c|c|c|c|}
\hline \multirow[b]{2}{*}{ Regime } & \multicolumn{2}{|c|}{$\begin{array}{c}\text { I. Benchmark Model } \\
\text { (Restricted Model of } \\
\text { table 1) }\end{array}$} & \multicolumn{2}{|c|}{$\begin{array}{l}\text { II. Replace inflation } \\
\text { with money growth }\end{array}$} & \multicolumn{2}{|c|}{$\begin{array}{l}\text { III. Include both } \\
\text { inflation and money } \\
\text { growth }\end{array}$} \\
\hline & Pre-crisis & $\begin{array}{l}\text { Post } \\
\text { Crisis }\end{array}$ & Pre-crisis & $\begin{array}{l}\text { Post } \\
\text { Crisis }\end{array}$ & Pre-crisis & $\begin{array}{l}\text { Post } \\
\text { Crisis }\end{array}$ \\
\hline Constant & $\begin{array}{c}-\mathbf{- 1 . 3 9 8} \\
0.00\end{array}$ & $\begin{array}{c}\mathbf{0 . 0 8 2} \\
0.42\end{array}$ & $\begin{array}{c}-\mathbf{- 1 . 1 6 0} \\
0.00\end{array}$ & $\begin{array}{c}\mathbf{0 . 0 8 2} \\
0.42\end{array}$ & $\begin{array}{c}-1.29 \\
0.00\end{array}$ & \\
\hline Lagged int rate & $\begin{array}{r}\mathbf{0 . 9 7 9} \\
0.00\end{array}$ & $\begin{array}{c}\mathbf{0 . 7 1 6} \\
0.00\end{array}$ & $\begin{array}{c}\mathbf{0 . 9 8 5} \\
0.00\end{array}$ & $\begin{array}{c}\mathbf{0 . 7 1 6} \\
0.00\end{array}$ & $\begin{array}{l}\mathbf{0 . 9 8} \\
0.00\end{array}$ & \\
\hline $\begin{array}{l}\text { Lagged change in } \\
\text { interest rate }\end{array}$ & $\begin{array}{c}-0.273 \\
0.00\end{array}$ & & $\begin{array}{c}-0.256 \\
0.00\end{array}$ & & $\begin{array}{c}-0.278 \\
0.00\end{array}$ & \\
\hline Inflation & $\begin{array}{c}\mathbf{0 . 0 5 3} \\
0.00\end{array}$ & & & & $\begin{array}{c}\mathbf{0 . 0 3 1} \\
0.10\end{array}$ & \\
\hline Money Growth & & & $\begin{array}{c}\mathbf{0 . 0 1 3} \\
0.02\end{array}$ & & $\begin{array}{c}\mathbf{0 . 0 1 0} \\
0.15\end{array}$ & \\
\hline PMI & $\begin{array}{c}\mathbf{0 . 0 2 6} \\
0.00\end{array}$ & & $\begin{array}{c}\mathbf{0 . 0 2 2} \\
0.00\end{array}$ & & $\begin{array}{c}\mathbf{0 . 0 2 3} \\
0.00\end{array}$ & \\
\hline $\begin{array}{l}\text { Nominal effective } \\
\text { exchange rate }\end{array}$ & $\begin{array}{c}-\mathbf{0 . 0 0 5} \\
0.05\end{array}$ & & $\begin{array}{c}-\mathbf{0 . 0 0 8} \\
0.02\end{array}$ & & $\begin{array}{c}-0.007 \\
0.03\end{array}$ & \\
\hline $\begin{array}{l}\text { Standard deviation of } \\
\text { error term }\end{array}$ & $\begin{array}{c}\mathbf{0 . 1 0 6} \\
0.00\end{array}$ & $\begin{array}{c}\mathbf{0 . 0 8 8} \\
0.00\end{array}$ & $\begin{array}{c}\mathbf{0 . 1 0 7} \\
0.00\end{array}$ & $\begin{array}{c}\mathbf{0 . 0 8 8} \\
0.00\end{array}$ & $\begin{array}{c}\mathbf{0 . 1 0 6} \\
0.00\end{array}$ & $\begin{array}{c}\mathbf{0 . 0 8 8} \\
0.00\end{array}$ \\
\hline Speed (K) & & & $\begin{array}{c}\mathbf{0 . 5 6 0} \\
0.29\end{array}$ & & $\begin{array}{l}\mathbf{0 . 5 2} \\
0.33\end{array}$ & \\
\hline Switching date $(\lambda)$ & & & $\begin{array}{c}225.67 \\
0.00\end{array}$ & & $\begin{array}{c}225.64 \\
0.00\end{array}$ & \\
\hline $\begin{array}{l}\text { Log likelihood } \\
\text { Posterior Odds Ratio vs } \\
\text { Benchmark }\end{array}$ & & & 110 & & 111.73 & \\
\hline $\begin{array}{l}\text { Log Likelihood test of } \\
\text { restrictions (p-value) }\end{array}$ & & & & & & \\
\hline
\end{tabular}

Notes: p-values in italics (for space reasons standard errors are not reported)

Blank cell indicates a coefficient restricted to zero; coefficient in the middle of a column indicates common coefficient in first and second periods.

Liklihood test treats I as restricted form of III 
Table A2: Alternative Regime Switches

\begin{tabular}{|c|c|c|c|c|c|c|c|}
\hline \multirow[b]{2}{*}{ Regime } & \multicolumn{2}{|c|}{$\begin{array}{l}\text { A. Benchmark } \\
\text { Model } \\
\text { (Restricted } \\
\text { Model of table 1) }\end{array}$} & \multicolumn{2}{|c|}{$\begin{array}{l}\text { B. } \text { Reaction to all } \\
\text { variables bar } \\
\text { lagged interest } \\
\text { rate constant }\end{array}$} & \multirow[t]{2}{*}{$\begin{array}{l}\text { C. Single } \\
\text { regime: no } \\
\text { change in } \\
\text { coefficients }\end{array}$} & \multicolumn{2}{|c|}{$\begin{array}{c}\text { D. Discrete } \\
\text { break in October } \\
2008\end{array}$} \\
\hline & $\begin{array}{l}\text { Pre- } \\
\text { crisis }\end{array}$ & $\begin{array}{l}\text { Post } \\
\text { Crisis }\end{array}$ & $\begin{array}{l}\text { Pre- } \\
\text { crisis }\end{array}$ & $\begin{array}{l}\text { Post } \\
\text { Crisis }\end{array}$ & & $\begin{array}{l}\text { Pre- } \\
\text { crisis }\end{array}$ & $\begin{array}{l}\text { Post- } \\
\text { crisis }\end{array}$ \\
\hline Constant & $\begin{array}{c}-\mathbf{1 . 3 9 8} \\
0.00\end{array}$ & $\begin{array}{c}\mathbf{0 . 0 8 2} \\
0.42\end{array}$ & $\begin{array}{c}-\mathbf{1 . 0 7 4} \\
0.00\end{array}$ & $\begin{array}{c}-\mathbf{0 . 8 2 6} \\
0.00\end{array}$ & $\begin{array}{c}-\mathbf{1 . 2 4 7} \\
0.00\end{array}$ & $\begin{array}{c}\mathbf{- 1 . 4 8 3} \\
0.00\end{array}$ & $\begin{array}{l}\mathbf{0 . 0 3} \\
0.78\end{array}$ \\
\hline Lagged int rate & $\begin{array}{r}\mathbf{0 . 9 7 9} \\
0.00\end{array}$ & $\begin{array}{c}\mathbf{0 . 7 1 6} \\
0.00\end{array}$ & $\begin{array}{c}\mathbf{0 . 9 8 6} \\
0.00\end{array}$ & $\begin{array}{c}\mathbf{0 . 7 5 9} \\
0.00\end{array}$ & $\begin{array}{c}\mathbf{0 . 9 7 1} \\
0.00\end{array}$ & $\begin{array}{c}\mathbf{0 . 9 7 9} \\
0.00\end{array}$ & $\begin{array}{c}\mathbf{0 . 7 7 7} \\
0.00\end{array}$ \\
\hline $\begin{array}{l}\text { Lagged change in } \\
\text { interest rate }\end{array}$ & $\begin{array}{c}-0.273 \\
0.00\end{array}$ & & & & $\begin{array}{c}-0.027 \\
0.69\end{array}$ & $\begin{array}{c}-\mathbf{0 . 2 8 7} \\
0.00\end{array}$ & \\
\hline Inflation & $\begin{array}{c}\mathbf{0 . 0 5 3} \\
0.00\end{array}$ & & & & $\begin{array}{c}\mathbf{0 . 0 0 3} \\
0.85\end{array}$ & $\begin{array}{c}\mathbf{0 . 0 4 2} \\
0.00\end{array}$ & \\
\hline PMI & $\begin{array}{c}\mathbf{0 . 0 2 6} \\
0.00\end{array}$ & & & & $\begin{array}{c}\mathbf{0 . 0 0 3} \\
0.00\end{array}$ & $\begin{array}{c}\mathbf{0 . 0 2 8} \\
0.00\end{array}$ & \\
\hline $\begin{array}{l}\text { Nominal effective } \\
\text { exchange rate }\end{array}$ & $\begin{array}{c}-0.005 \\
0.05\end{array}$ & & & & $\begin{array}{c}-\mathbf{0 . 0 0 3} \\
0.21\end{array}$ & $\begin{array}{c}-0.005 \\
0.07\end{array}$ & \\
\hline $\begin{array}{l}\text { Standard deviation of } \\
\text { error term }\end{array}$ & $\begin{array}{c}\mathbf{0 . 1 0 6} \\
0.00\end{array}$ & $\begin{array}{c}\mathbf{0 . 0 8 8} \\
0.00\end{array}$ & $\begin{array}{c}\mathbf{0 . 1 0 0} \\
0.00\end{array}$ & $\begin{array}{c}\mathbf{0 . 1 0 0} \\
0.00\end{array}$ & $\begin{array}{c}\mathbf{0 . 1 2 5} \\
0.00\end{array}$ & $\begin{array}{c}\mathbf{0 . 1 0 9} \\
0.00\end{array}$ & $\begin{array}{c}\mathbf{0 . 1 0 8} \\
0.04\end{array}$ \\
\hline Speed (K) & & & & & N/A & $\begin{array}{r}1 \\
(\mathrm{imp}\end{array}$ & ed) \\
\hline Switching date $(\lambda)$ & & & & & N/A & $\begin{array}{r}22 \\
(\mathrm{imp}\end{array}$ & ed) \\
\hline $\begin{array}{l}\text { Log likelihood } \\
\text { Posterior Odds Ratio vs } \\
\text { Benchmark }\end{array}$ & & 545 & & & 86.05 & & \\
\hline $\begin{array}{l}\text { Log Likelihood test of } \\
\text { restrictions vs } \\
\text { benchmark (p-value) }\end{array}$ & & & & & 0.000 & & \\
\hline
\end{tabular}

Notes: $p$-values in italics (for space reasons standard errors are not reported) 
Blank cell indicates a coefficient restricted to zero; coefficient in the middle of a column indicates common coefficient in first and second periods.

Odds ratio equals the ratio of the likelihood function for the alternative model to the likelihood function of the benchmark model

Liklihood test treats $\mathrm{C}$ and $\mathrm{D}$ as restricted forms of benchmark model 